inclusion of very serious assumptions in the line of reasoning", whether he was blaming typology or me. If the former, it is rather a sweeping criticism to apply to a method which every archæologist must use constantly in any study of various members of closely related industries.

Comparative typology between these related groups is the study of the latest stages of advance in shape, size, utility and technical skill in the making of tools of those groups. Though the typological stages may be, and frequently are, modified by local differences in flaking technique, the latter is seldom sufficient to constitute a real difference; for example, the Acheulean of one area may have reached stage $D$ at one period; in another area it may also have reached stage $D$, typologically, but here it may be $D+$ or $D$ - certain differences in technique. The primary value is the same.

If, however, I myself am accused of making unjustifiable assumptions, I can only imagine that the statement to which Prof. Dreyer took exception was that the Clacton-like platforms in the Uganda Early Acheulean were due to the use of a similar type of core technique for detaching flakes; also, that the use of such a core technique in a handaxe industry did not necessarily imply the presence of proto-Levalloisian, but that it might be due to borrowing from Clacton or other flake industries. Before even this can be definitely stated, however, the presence of true Clacton must be proved, and this requires a pure site, unmixed with any handaxe industry.

In Uganda, three stages of Acheulean provide ample evidence that the numerous Clacton-like flakes of all sizes merely represent the waste from cores and handaxes. Personal experiment in obtaining large flakes from coarse-grained, hard and tough rocks shows that the easiest way, usually, was to choose a block, some of the edges of which formed acute angles. Then, either by direct percussion or by striking the core downwards on an anvil stone, flakes, the size of which could be to some extent regulated, were readily detached. These almost always had the 'Clacton angle'. As they also had acute-angled edges, the secondary flakes struck from them in the trimming of handaxes also possessed the 'Clacton angle'.

Now, since the large-core technique was in use in South Africa since Lower Stellenbosch times, it is not surprising that by the time of the Upper Stellenbosch the technique had advanced a stage further, so that, by preparation of the cores, workmen were better able to regulate the size of the primary flakes required, which may account for the peculiar cores of the Victoria West variation.

African Prehistoric Research Exper. T. O'BRIEN. c/o Standard Bank of South Africa,

$$
\text { Kampala, Uganda. }
$$$$
\text { Jan. } 1 \text {. }
$$

'NATURE, 136, 872, Nov. $30,1935$.

iNATURE, 136, 475, Sept. 21, 1935.

\section{Amino Acid Content of Plants at Different Stages of Growth}

INCREASING attention has lately been paid to the composition of the protein constituents of the green plints. Important work has been done in this field, particularly by Chibnall and Wright. In the present letter we wish to direct attention to an important but rather neglected question in the study of the plant proteins. One of us (A. I. V.) has already referred to this question in the discussion on the chemistry of grass crops at the recent Norwich meeting of the British Association.

During recent years, we have followed the changes in the tryptophane and aspartic acid content of green plants and found that the percentage values of these compounds (total $\mathrm{N}$ basis) vary considerably during the different stages of growth. Thus, for example, the tryptophane content of peas and clover is very much higher at an early stage, just before blooming, than during the flowering stage. The same is true of the aspartic acid values. They show a second rise first at a late stage of growth when the seeds are already beginning to form. According to the literature, Klein and Tauböck ${ }^{2}$ have noted significant variations in the arginine content of plants at different stages of development.

A direct comparison of proteins from different plants is rendered difficult by the fact that the proportions of the different amino acids vary during the development of the plant.

The variations in the amino acid values at different stages of growth can be explained either by assuming : (a), that the plants contain several different proteins, each with a definite composition, and that the mutual proportions of these proteins vary throughout the period of growth; or $(b)$, that in the growing plant the protein has no fixed composition but that new amino acid groups are continuously being incorporated with the growing protein molecule.

As regards the analytical procedure, we consider it very important that the amino acids should be determined directly from the plant material, since there are no methods available by which the proteins can be completely extracted from the fresh material without changes in the amino acids. The tryptophane and aspartic acid determinations referred to above were made directly from the fresh material.

Artturi I. Virtanen.

Laboratory of the Foundation

$$
\text { T. LAINE. }
$$

for Chemical Research,

Helsingfors.

Jan. 9

${ }^{1}$ A. I. Virtanen, J. Soc. Chem. Ind., 54, No. 47 (1935).

2 Biochem. Z., 251, 10 (1932).

\section{Utilisation of Sugars and Polyhydric Alcohols by the Adult Blowfly}

IT is known that houseflies ${ }^{1}$ and blowflies ${ }^{2}$ can be kept alive perfectly well on a diet consisting of canesugar and water alone. Addition of protein is only essential for the development of eggs. At a temperature of $26^{\circ} \mathrm{C}$., Calliphora erythrocephala on a diet of pure water lives only two to three days, on canesugar and water one to two months. If cane-sugar is replaced by other sugars, polysaccharides or polyhydric alcohols, it is found that many substances support adult life equally well. One (sorbitol) is actually much better, others are not so good as canesugar; whereas many substances are not utilised at all.

The following is a summary of the results obtained so far :

Monosaccharides : utilised : glucose, fructose, galactose, mannose; not utilised: sorbose. 